\title{
Assessment of Human Milk Intake by Breastfed Infants Using Deuterium Oxide Dose-to-Mother Technique in "Tumbuh Kembang Anak" Cohort, Indonesia
}

\author{
E.K. Winarno ${ }^{1 *}$, H. Winarno ${ }^{1}$, Susanto ${ }^{1}$, T. Fajarwati ${ }^{2}$ and T. Thomas ${ }^{3}$ \\ ${ }^{I}$ Center for Isotopes and Radiation Application, National Nuclear Energy Agency, \\ Jl. Lebak Bulus Raya No. 49, Jakarta 12440, Indonesia \\ ${ }^{2}$ Center for Research and Development of Health, National Institute of Health Research and Development, \\ The Ministry of Health, Jl. Percetakan Negara No. 29, Jakarta 10560, Indonesia \\ ${ }^{3}$ St. John's Research Institute, 100 Feet Rd, John Nagar, Koramangala, Bengaluru, Karnataka 560034, India
}

\section{ARTICLE INFO}

Article history:

Received 23 March 2018

Received in revised form 29 November 2018 Accepted 27 December 2018

\section{Keywords:}

Human milk intake

Isotopes deuterium oxide

Infants

Exclusive breastfeeding

Indonesia

\begin{abstract}
A B S T R A C T
Indonesia government has done the WHO recomendation that the infants should be exclusively breastfed for the first six months of life to achieve optimum growth, development and health. Nevertheless, the percentage of exclusive breastfed infants have not achieved the target yet and has not been scientifically quantified. The objective of the study is to measure the intake of human milk of Indonesian infants during first 6 months and to record the breastfeeding practices of mothers. Thirty healthy mother-infant pairs were recruited randomly for the cross-sectional study at "Tumbuh Kembang Anak" cohort in Bogor. Milk intake to the infant was measured using the deuterium oxide technique over 14 days. The interviews were done by members of team using the questionnaire to get the information on breastfeeding practice of respondents. The results showed that intake of human milk was $784 \pm 117 \mathrm{~g} . \mathrm{d}^{-1}$ (mean $\pm \mathrm{SD}$ ), $787 \pm 180 \mathrm{~g} . \mathrm{d}^{-1}$ for infants 3 and 6 moths of age. It showed that the milk intake were not different between 3 and 6 months. The body composition of mothers, age, or parityhad no effects on milk intake of infants, education of mothers ( 3 months aged, $\mathrm{P}=0.061, \mathrm{r}=-0.097$ and 6 months, $\mathrm{P}=0.616, \mathrm{r}=-0.095)$, infants of 3 months aged, $\mathrm{P}=0.200, \mathrm{r}=-0.290$ and 6 months, $\mathrm{P}=-0.078, \mathrm{r}=0.684)$. Body mass index of mother $(\mathrm{P}<0.05, \mathrm{r}=0.963)$ were correlated with the milk intake. About $53 \%$ of the lactating mothers started breastfeeding within less than one hour of delivery. Breast-milk intake of the Indonesian infants were documented using deuterium oxide-to-the-mother technique. In the current study concluded that the exclusive breastfeeding practices with 30 pairs of mother-infant still shows that the conditions of exclusive breastfeeding practices have not been properly adhered to by mothers who deliver babies. It is recommended that "mother and baby health officer" in Indonesia are increasingly promoting in order mothers in urban and rural areas to breastfeed exclusively for up to 6 months.
\end{abstract}

\section{INTRODUCTION}

Evidence of early life nutrition from prenatal period and throughout the first two years, known as the 'first 1000 days', impacts on consequent health

* Corresponding author

E-mail address: erminkk@batan.go.id

DOI: https://doi.org/10.17146/aij.2019.844 and functions in later life. Breastfeeding is an important strategy for public health to reduce maternal and babies morbidity and mortality, and to reduce health care costs [1]. Breast milk is the best source of nutrition for infants, therefore exclusive breastfeeding (EBF) for the first six months of life is recommended by the World Health Organization (WHO), followed by the introduction of appropriate 
complementary foods and continued breastfeeding until two years $[2,3]$.

In Indonesia, health research data based on Indonesia Basic Health Research 2013 showed that $34.5 \%$ of infants had gotten breastfed since early (first 24 hours after birth), $50 \%$ of infants aged less than one month had gotten exclusive breastfed. At the age of 6 months infants only remaining $30.2 \%$ who received only human milk [4]. According to A. Halim et al. [5], exclusive breastfeeding tends to have a protective effect, but statistically not significant. It is further said that exclusive breastfeeding is still highly recommended because it has many benefits and advantages over formula milk. According to A. Devriany et al. [6] there is a significant difference on mean length changes between neonate infants group given exclusive breastfeeding and neonate infant group given non-exclusive breastfeeding with a value of $\mathrm{p}<0.05$.

Monitoring of exclusive breast feeding is an indicator of infant feeding practice. It is difficult to accurately assess exclusive breastfeeding rates in large scale surveys. The 24-hour recall method substantially over estimates the prevalence of exclusive breastfeeding because the data are based only on feeding practices for the day preceding the survey. The deuterium oxide dose-to-mother technique can be used to assess intake of human milk by breastfed babies. This technique is more accurate than the conventional methods for assessing breast milk intakes and it can be applied in the field setting and it is safe for both mother and baby. The conventional method to determine the amount of breastmilk received by infant is using graphimetry method (the amount of breastmilk received by infant $=$ the weight of the infant after breastfeeding - the weight of the infant before breastfeeding). Most importantly, the intake of water from sources other than human milk by the infant can be estimated, whether the infant is exclusively breastfed or not, it can be verified using the dose-to-mother technique as the gold standard. Infants who are infrequently given liquids or foods but were not given any during the previous day are classified as exclusively breastfed.

A study in Bangladesh by Moore et al. [7] showed that seventy-five of the 98 subjects reported exclusive breastfeeding. Using the since birth recall methods, exclusive breastfeeding rates was over estimated due to the difficulty in accurately recalling practices that may have occurred months prior to the interview. An over estimation of exclusively breastfed by recall method vs the stable isotope method (75 vs $11 \%$ ) was reported by IAEA [8]. A study in India, despite intensive counseling in a baby-friendly hospital, early complementary feeding was observed at home. Complementary feeding was introduced as early as one month among $44 \%$ of the infants and only $14.2 \%$ remained as exclusively breastfed by month 6 . Intake of breast milk (BM) water significantly declined from 166 to $87 \mathrm{ml} / \mathrm{kg} / \mathrm{d}$ and non-breast milk (NBM) water significantly increased from 23 to $51 \mathrm{ml} / \mathrm{kg} / \mathrm{d}$ from the first month to the 6th month $(\mathrm{P}<0.001)$. Discrepancies in the reported exclusive breastfeeding and measured $\mathrm{BM}$ water by the deuterium oxide dose-to-mother method were found. At 3 months, this discrepancy was $77 \%$ vs $10 \%$, and at 6 months, it was $36 \%$ vs $14.2 \%$, respectively [9].

The present study was carried out to measure the intake of human milk of Indonesian infants aged 3 and 6 months, and also to access whether the infants actually obtained exclusive breastfeeding or not. Respondents selected from the maternal and child "Tumbuh Kembang Anak" cohort of National Institute of Health Research and Development, Bogor, Indonesia. This Cohort was established in 2011 with the aim of studying the main risk factors for impaired child growth and development. It is necessary to conduct a prospective cohort study on child growth and development, from the fetus until the child is 18 years old. In 2011 a cohort of child development research was conducted according to the stage of child growth. In 2012 conducted fetal growth cohort; in 2013 the cohort grew up babies born until the age of 11 months; year 2014 - 2016 child development cohort aged 12 - 35 months; year 2017 - 2019 cohort of child development aged 36 - 59 months; year 2020 - 2026 cohort of child development aged 6 - 12 years, and year 2026 2032 cohort of child development aged 13-18 years.

\section{THEORY}

Intake of human milk and water from sources other than human milk can be assessed by fitting the deuterium enrichment data to a model for water turnover in the mother and the baby. Human milk intake by the baby is calculated from the flow of water from the mother to the baby as described in Fig. 1 [8].

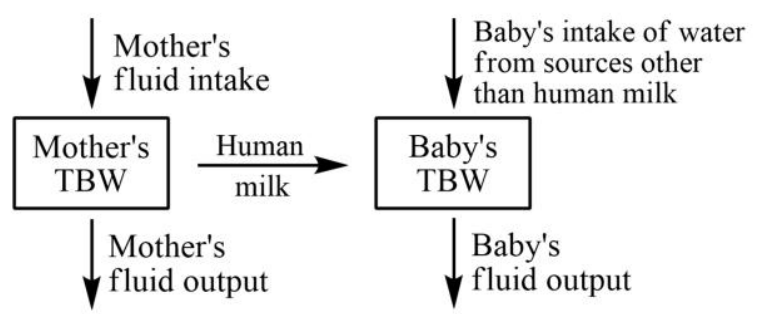

Fig. 1. Two compartments steady state model of water flow in a mother-baby pair [8] TBW: total body water. 


\section{EXPERIMENTAL METHODS}

\section{Subjects}

Thirty mother-infant pairs, stratified across 3 until 6 months, were randomly selected from the maternal and child "Tumbuh Kembang Anak" cohort of National Institute of Health Research and Development, Bogor, Indonesia. All infants must be EBF in order to participate in the study. Prior to enrollment, eligibility of the mother-infant pairs was tested using a brief demographic and health questionnaire. Inclusion criteria was mother who exclusive breastfeeding, parity no more than 3 , infant aged 3 months \pm 7 days, nutrition status WHZ more than -2. Meanwhile, exclusion criteria was twin baby or more, low birth weight, baby with oedema, mother with fluid retention disease, and mother with smoking and drinking alcohol. Study protocol was approved by the Ethical Review Committee of the Ministry of Health, Jakarta, Indonesia, and additional institutional approval were obtained from Health Office of Bogor City, West Java, Indonesia. Written informed consent was obtained from the mothers after explaining the procedures, objective of the research, as well as expected outcomes and impacts.

\section{Human milk intake measurement}

The deuterium oxide to-the-mother technique was used to measure human milk intake over a period of $14 \mathrm{~d}$ [11]. Sampling was performed according to the procedure of IAEA [8]. Mothers (with light clothing) and the infants (nude) were weighed using standard scales. Mothers weights were measured to the nearest $0.1 \mathrm{~kg}$ and infants to the nearest $5 \mathrm{~g}$. Infant length was measured using an infanto meter to the nearest $1 \mathrm{~mm}$. Predose samples of the mother's and infant's saliva $(1.5-2.0 \mathrm{~mL})$ were collected for ${ }^{2} \mathrm{H}$ analysis by isotope ratio mass spectrometry. On day 1 , an accurately measured dose of $10 \mathrm{~g} \mathrm{D}_{2} \mathrm{O}$ (99.9\% $\mathrm{D}_{2} \mathrm{O}$; Sigma-Aldrich Corp.) was administered orally to the mother. The mothers remained in the sitting position for the next 5 - 10 min. Mother's saliva samples were collected on days 1 ( $5 \mathrm{~h}$ postdose), 4, and 14. The saliva samples were taken from the sterile cotton ball which were kept in the mother mouth for several minutes according to Bandara method et al. [11]. The saliva was expressed from the wet cotton wool ball using a $10-\mathrm{mL}$ syringe. Infant's urine samples were collected at each of the follow-up visits on days 1, 2, 3, 4, 13 and 14 postdosing. Saliva samples were frozen at $-20^{\circ} \mathrm{C}$, stored, and transported to the St. Johns Research Institute, Bangaluru, India, for isotopic analyses. Infant's body weights were measured again on day 14 to monitor growth.

\section{Analysis of deuterium enrichment}

The enrichment of deuterium oxide in saliva samples were reducted to hydrogen gas using Pt and the hydrogen produced was transferred into Thermo Delta Advantage continuous-flow Isotope Ratio Mass Spectrometer system [12].

\section{Breastfeeding practices}

Participants characteristics and demographics were put in table as mean \pm SD. Subject collection was conducted using questionnaire provided by the interviewer.

\section{The calculation}

Curves were generated using the deuterium data obtained from the saliva samples and the time elapsed after the isotopes were administered to mothers. The breast milk intake was calculated by using the equation in Microsoft Excel as described by V. Lopez-Teros et al. [10] and Bandara et al. [11]. The collected data of $\mathrm{D}_{2} \mathrm{O}$ concentration were input into a Microsoft Excel Spreadsheet supplied by the IAEA and pre-programmed for the calculation of the milk intake according to equations 1 and $2[8,11]$ :

$$
\begin{aligned}
& \text { Equation for mothers : } \mathrm{E}_{m(\mathrm{t})}=\mathrm{E}_{m(0)} \mathrm{e}^{-K m m-1} \\
& \begin{aligned}
\text { Equation for infants }: \mathrm{E}_{b(t)}= & \mathrm{E}_{m(0)}\left(\mathrm{F}_{b m} / \mathrm{V}_{b}\right)\left(\mathrm{e}^{-K m m-1}-\mathrm{e}^{(F b b / V b) t}\right) / \\
& {\left[\left(F_{b b} / V_{b}\right)-K m m\right] }
\end{aligned}
\end{aligned}
$$

where, $\mathrm{E}_{m(0)}$ is isotope enrichment of the sample at time 0 (expressed as mg. $\mathrm{kg}^{-1}$ ); $\mathrm{E}_{m(t)}$ is isotope enrichment of a sample at time $t$ (expressed as mg. $\left.\mathrm{kg}-1^{-1}\right) ; t$ is time elapsed since administration of the time 0 (expressed as d); $\mathrm{K}_{m m}$ is water turnover in the mother (expressed as g.d ${ }^{-1}$ ); $\mathrm{E}_{b(t)}$ is isotope enrichment of the sample taken at time $t$ (expressed as $\left.\mathrm{m} . \mathrm{kg}^{-1}\right) ; \mathrm{F}_{b m}$ is flow of water from the mother to the infant trough breast milk (expressed as $\mathrm{kg} . \mathrm{d}^{-1}$ ); $\mathrm{V}_{b}$ is distribution space of infant (expressed as $\mathrm{kg}$ ); $\mathrm{K}_{m m}$ is water turnover in the infant (expressed as $\mathrm{g}$. $\left.\mathrm{d}^{-1}\right) ; \mathrm{F}_{b b}$ is total water loss in infant (expressed as $\left.\mathrm{kg} \cdot \mathrm{d}^{-1}\right)$. This method is based on the assumption that $\mathrm{V}_{b}$ is changed linierly with weight over the course of the study period and is related to the infant weight (W) in kilograms by $\mathrm{V}_{b}=0.84 \mathrm{x} \mathrm{W}^{0.82}$.

\section{Statistical analysis}

Respondents characteristics and demographics were put in table as mean \pm SD . The association between breast milk intake and anthropometric characteristics of subjects was assessed by Pearson correlation. All statistical procedures were performed using the Statistical 
Package for Social Sciences (version 22, SPSS, Inc.) at $P$ value of 0.05 .

\section{RESULTS AND DISCUSSION}

A total of 30 mother-infant pairs were recruited in the study to represent infants of 3 and 6 months age.

\section{Description of mother-infant pairs}

The characteristics of the mother-infant pairs is shown at Table 1 and Table 2. The age of the mothers was $30.8 \pm 5.2 \mathrm{y}$. Parity were first, 2 and 3 . The majority of the mothers $(60 \%)$ had passed the high school. Average of body mass index (BMI) of mothers were $25 \mathrm{~kg} . \mathrm{m}^{2}$ were not unchanged at infants aged 3 to 6 months. Most of mothers were graduated high school and most of them were unemployed (96.7\%), they should have more time to give breast milk to their babies.

Table 1. Mother characteristics.

\begin{tabular}{lc}
\hline \multicolumn{1}{c}{ Characteristic } & Value \\
\hline Weight, $k g$ & \\
3 months & $59.2 \pm 10.9$ \\
6 months & $59.1 \pm 11.4$ \\
Height, cm & \\
3 months & $151.9 \pm 5.3$ \\
6 months & $152.3 \pm 5.2$ \\
BMI, kg.m ${ }^{2}$ & \\
3 months & $25.6 \pm 4.1$ \\
6 months & $25.4 \pm 4.2$ \\
Age, $y, \%$ & \\
$20-25$ y & $5(16.7)$ \\
25.5- 30 y & $10(33.3)$ \\
$30.5-40 y$ & $13(43.3)$ \\
$>40$ y & $2(6.7)$ \\
Parity, $n, \%$ & \\
& $4(13.3)$ \\
& $12(40.0)$ \\
Education, $n, \%$ & $14(46.7)$ \\
Primary School & \\
Junior High School & $4(13.3)$ \\
High School & $8(26.7)$ \\
University & $15(50.0)$ \\
Employment, $n, \%$ & $3(10.0)$ \\
Unemployed & \\
Employed & $29(96.7)$ \\
\hline
\end{tabular}

Table 2. Infant Characteristics.

\begin{tabular}{lcc}
\hline \multirow{2}{*}{ Characteristic } & \multicolumn{2}{c}{ Value } \\
\cline { 2 - 3 } & & Goys \\
\hline Weight, $k g$ & $6.57 \pm 0.7$ & $5.50 \pm 0.7$ \\
3 months & $7.93 \pm 0.7$ & $6.48 \pm 0.8$ \\
6 months & & \\
Length, cm & $62.20 \pm 1.9$ & $59.08 \pm 2.4$ \\
3 months & $66.08 \pm 2.6$ & $63.89 \pm 2.6$ \\
6 months & & \\
BMI, kg.m ${ }^{2}$ & $16.6 \pm 1.2$ & $15.8 \pm 1.6$ \\
3 months & $17.9 \pm 2.1$ & $15.6 \pm 2.0$ \\
6 months & $3.4 \pm 0.5$ & $3.2 \pm 0.5$ \\
Birth weight, $k g$ & $49.8 \pm 1.9$ & $48.6 \pm 1.69$ \\
Birth length, cm & & \\
\hline
\end{tabular}

\section{Body composition of the mothers}

Kinetic data of $\mathrm{D}_{2} \mathrm{O}$ concentration in mother's and baby's saliva are shown in Fig. 2 and the calculation result in Table 3 (Kinetic data of the mothers and the infants based on the deuterium oxide-to mother model). There was no significant difference found in total body water (TBW), fat mass (FM), fat free mass, and percentage of fat mass ( $\%$ FM) between mothers of infants aged 3 and 6 months.

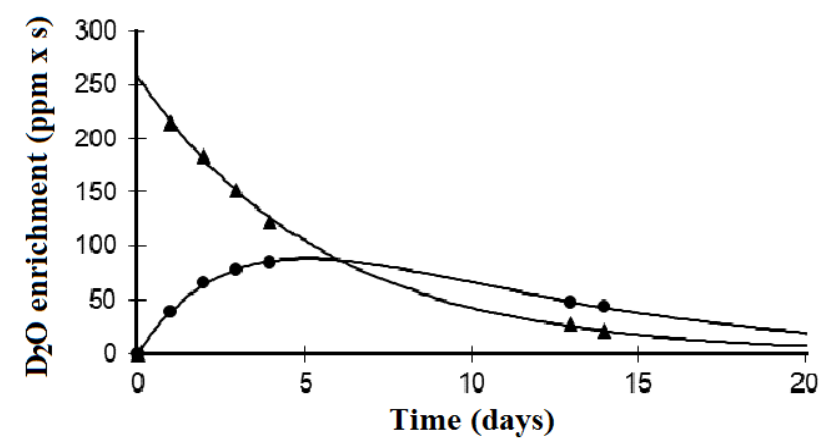

Fig. 2. Kinetic of $\mathrm{D}_{2} \mathrm{O}$ concentration in mother's (- $\left.\boldsymbol{\Delta}_{-}\right)$and baby's saliva (-๑-) at days of observation.

\section{Breast-milk intake}

Table 3 also summarizes the kinetic data of the mothers and infants based on the deuterium oxide - to mother model. The human milk intake is not different between 3 and 6 months $(P=0.797)$. The nonmilk (oral) intake increased with age $(\mathrm{P}<0.001)$. The square root of the mean square error (expressed as $\mathrm{mg}^{2} . \mathrm{kg}^{2}$ ) of the model was very small, indicative of good fit of data to the model. Milk intake was not affected by the mother's age $(\mathrm{P}=0.938)$, parity $(\mathrm{P}=0.717)$, body weight $(\mathrm{P}=0.163), \mathrm{BMI}(\mathrm{P}=0.481), \% \mathrm{FM}(\mathrm{P}=0.175)$. However, milk intake was positively related to the mother's education $(\mathrm{P}=0.366)$. Furthermore, milk intake was positively associated with BMI $(\mathrm{P}<0.04, \mathrm{r}=0.41)$ and higher for boyinfants $(866$ vs $742, \mathrm{P}=0.031$ ).

\section{Infant's growth}

Infant's milk intake, weight gain, weightforage $\mathrm{z}$ scores, length-for-age $\mathrm{z}$ scores, and ponderal index of boy and girl infants are shown in Table 4.

\section{Breastfeeding practices}

Breastfeeding practices of the mothers are shown in Table 3 . There were $53 \%$ the lactating mothers commenced breastfeeding within $\leq 1$ hour of the delivery. About $100 \%$ of the mothers continued to give exclusively breastfed up to 6 months. 
Table 3. Kinetic data of the mothers and the infants based onthe deuterium oxide-to mother model. ${ }^{*}$

\begin{tabular}{|c|c|c|}
\hline Index & 3 months & 6 months \\
\hline \multicolumn{3}{|l|}{ Kinetic data of the mother } \\
\hline D space $\left(V_{m}\right), k g$ & $36.0 \pm 5.2(26.2-46.2)$ & $37.4 \pm 5.0(27.8-49.0)$ \\
\hline TBW, kg & $34.6 \pm 5.0(25.1-44.4)$ & $35.9 \pm 4.8(26.7-47.0)$ \\
\hline Fat-Free Mass, kg & $47.3 \pm 6.8(34.4-60.6)$ & $49.1 \pm 6.6(36.4-64.2)$ \\
\hline Fat Mass, kg & $11.3 \pm 6.2(2.4-25.8)$ & $10.0 \pm 7.9(-7.6-26.6)$ \\
\hline Fat Mass, $\%$ & $18.4 \pm 8.1 \quad(4.0-32.6)$ & $15.5 \pm 11.2(-15.4-32.7)$ \\
\hline Water intake, $\mathrm{kg} \cdot \mathrm{d}^{-1}$ & $5.0 \pm 0.9 \quad(3.0-7.0)$ & $5.1 \pm 1.0(3.3-8.5)$ \\
\hline $\begin{array}{l}\mathrm{D}_{2} \mathrm{O} \text { concentration in mother's } \\
\text { body water at time } 0, \mathrm{mg} \cdot \mathrm{kg}^{-1}\end{array}$ & $284 \pm 42(217-382)$ & $270 \pm 35(205-362)$ \\
\hline \multicolumn{3}{|l|}{ Kinetic data of the infants } \\
\hline Human milk intake, g. $\mathrm{d}^{-1}$ & $784 \pm 117(525-1105)$ & $787 \pm 180(320-1246)$ \\
\hline Water input from milk, g.d ${ }^{-1}$ & $753 \pm 112(505-1062)$ & $756 \pm 173(308-1198)$ \\
\hline Water used in growth, g.d $^{-1}$ & $12 \pm 18 \quad(-6-101)$ & $1 \pm 10(-47-10)$ \\
\hline Total water output, g.d $\mathrm{d}^{-1}$ & $841 \pm 128(606-1193)$ & $938 \pm 168(645-1386)$ \\
\hline Non-oral water intake, g.d ${ }^{-1}$ & $54 \pm 8 \quad(39-79)$ & $65 \pm 29(41-210)$ \\
\hline Non-milk oral intake, g. $\mathrm{d}^{-1}$ & $43 \pm 48 \quad(-63-142)$ & $140 \pm 144(-93-648)$ \\
\hline Square root MSE, mg.kg ${ }^{-1}$ & $11 \pm 8 \quad(4-49)$ & $20 \pm 26(4-115)$ \\
\hline
\end{tabular}

*Values are means 6 SDs (range), $n=15$

Table 4. Human milk intake and growth of the boy and girl infants.

\begin{tabular}{lcccc}
\hline \multirow{2}{*}{ Variables } & \multicolumn{2}{c}{3 months } & \multicolumn{2}{c}{6 months } \\
\cline { 2 - 5 } & Boy $(n=13)$ & Girl $(n=17)$ & Boys $(n=13)$ & Girls $(n=17)$ \\
\hline Human milk intake, ${\mathrm{g} . \mathrm{kg}^{-1} . \mathrm{d}^{-1}}^{131 \pm 23}$ & $136 \pm 19$ & $111 \pm 23$ & $113 \pm 28$ \\
Weight gain, g.d $^{-1}$ & $23 \pm 9$ & $14 \pm 12$ & $5 \pm 12$ & $7 \pm 8$ \\
Weight-for-age z score & $0.26 \pm 0.98$ & $-0.53 \pm 0.98$ & $0.13 \pm 0.73$ & $-0.84 \pm 1.02$ \\
Lenght-for-age z score & $0.43 \pm 0.95$ & $-0.31 \pm 1.03$ & $0.07 \pm 0.59$ & $-0.84 \pm 0.88$ \\
Ponderal index $^{2}$, g.cm $^{3}$ & $2.73 \pm 0.19$ & $2.67 \pm 0.28$ & $2.62 \pm 0.2$ & $2.58 \pm 0.22$ \\
\hline
\end{tabular}

Since 2002 to 2012 , the exclusively breastfed in Indonesia generally increased slightly from 40.0 to $42.0 \%$ [4], while in 2013, the exclusively breastfed significantly increased to $54.3 \%$ (25.2 $79.7 \%$ ), with 19 provinces had the percentage of exclusively breastfed $>54.3 \%$. The weight gain of infants aged $0-6$ months increased by $150-210$ grams/week and based on the growth curve published by the National Center for Health Statistics (NCHS) that cited by Norma [13]. This study was carried out cross-sectional study conducted in rural and urban areas of Bogor, West Java, Indonesia. The life of the respondents were low- and middle economy, majority of the respondents represented the low socioeconomic class. Based on the results of Nutrition Status Monitoring by Pauzi [14], it is known that the percentage of exclusive breastfeeding in the last 24 hours and without a history of food and drink other than breast milk at the age of 6 months in Bogor Regency was $58.2 \%$. While, study by Triatmaja in Bogor city - Indonesia [15], the exclusive breastfeeding decreased annually, in 2012 the number of exclusive breastfeeding reached $66.5 \%$, but decreased significantly to $38.6 \%$ in
2013, then decreased drastically to $17.2 \%$ by 2014 . This decrease was allegedly caused by the lack of knowledge of midwives and mothers about Government Regulation of the RI No. 33 year 2012 which recommended exclusive breastfeeding for up to 6 months, but they still want to give the formulated milk to their infants. The mean duration of mothers giving exclusive breastfeeding is 4 months [16]. In Table 2, it was shown that infant's weight from 3 months to 6 months increased by $20.7 \%$ for boy infants and $17.8 \%$ for girl infants. The mothers do not directly breastfeed the infants in the first hours of birth because there are assumption that colostrum is a dirty liquid and can not be consumed, it can cause the babies to have fever, abdominal pain and cause stupidity. It was only $52 \%$ of mother gives colostrum to infants within 1 hours after birth [17].

Maternal education is very influential on the understanding of exclusive breastfeeding, the higher the mother's education will be more aware to give exclusive breastfeeding longer [18]. Research studied by Aziezah using 17 respondents of exclusive breastfeeding (EBF) group and 17 respondents of non-EBF group showed that most of 
EBF group received breast milk more than 15 minutes (categorized as good), meanwhile the nonEBF group mostly reveived breast milk less than 5 minutes (categorized as bad) every time they breastfeed [19].

Breast milk is the best source of nutrition for infants up to 6 months of age, accordingly WHO [2,3] and the Indonesian government [4] recommend that mothers breastfeed exclusivey to their infants up to the age of 6 months, without providing any additional food for 6 months. In interview, mothers assure the health officer that their infants are exclusive breastfed. To verify whether the infants have actually received exclusive breastfeeding or not, the IAEA and several countries had conducted the research to validate the questionnaire and interview model given to mothers who breastfed their infants. Validation of questionnaire and interview model were conducted by utilizing the stable isotope deuterium oxide given to the mothers. In Table 2, the average BMI of lactating mothers who joined in this study was $25 \mathrm{~kg} \cdot \mathrm{m}^{2}$ in infants aged 3 to 6 months. These data indicated that they had satisfactory nutritional status. Most of mothers graduated from senior high school. Table 3 shows the average of breast milk intake of exclusively breastfed infants aged 3 months $\left(784 \pm 117\right.$ g.day $\left.{ }^{-1}\right)$ and infants aged 6 months $\left(787 \pm 180\right.$ g.day $\left.^{-1}\right)$. These values are in accordance with th results of M. Mazariegos et al. that the amount of breast milk production by a lactating mother ranges from 733 to $840 \mathrm{~mL} \cdot \mathrm{d}^{-1}$ [20]. While, according to L.A.D. Ciampo et al. which cited by M.T.S. Andrade et al. also mentioned that in general the average of breast milk intake of well-nourished mothers is approximately 640 to $820 \mathrm{~mL} \cdot \mathrm{d}^{-1}$ [21]. In Mexico, brest milk intake in infants aged $0-2$ years was $758 \pm 185 \mathrm{~mL}$, and no difference was observed between urban and agricultural areas $(\mathrm{P}=0.067)$ [9]. Bandara reported that Sri Lanka infants who are exclusively breasfed during the first 6 mo of life receive adequate nutrition for growth with breast milk average intake was $802 \pm 156$ g.d $\mathrm{d}^{-1}[10]$. The result of this study showed Indonesian infants who are exclusively breastfed during the first 6 mo of life receive adequate nutrition for growth $\left(787 \pm 180\right.$ g.d $\left.{ }^{-1}\right)$. Among them, 23 infants received adequate amounts of breast milk for their growth $\left(700-1105\right.$ g.d $\left.\mathrm{d}^{-1}\right)$, however there were still 7 infants who received breast milk that not adequate enough. Comparison of weight gain of the Indonesian exclusively breastfed infants in the present study with that reported in Sri Lanka (23 vs 22) g. $\mathrm{d}^{-1}$ for boys and (14 vs 21) g. $\mathrm{d}^{-1}$ for girls at 3 months of age, and (5 vs 9.8) g.d $\mathrm{d}^{-1}$ for boys and (7 vs 12.2 ) g.d $\mathrm{d}^{-1}$ for girls at 6 months [9], it appeared that the weight gain of the Indonesian exclusively breastfed girl infants aged 3 months was smaller compared to EBF girls infants from Sri Lanka, as well as for boys and girls of 6 months age. This is presumably some babies were not enough getting breast milk, some of them had a fever, cough or flu, and their energy were used for motoric activities, so their weight gain were not significant. There was no significant difference in infant weight gain, even the average infant weight at 6 months decreased compared to 3 months. However, the length of the infant's body in the 6th month rose by $8.0 \%$ (boys) and $6.1 \%$ (girls) compared to the 3 rd month.

The average of non-milk oral intake in infants from 43 g.d $\mathrm{d}^{-1}$ (at 3 months) increased to $140 \mathrm{~g} . \mathrm{d}^{-1}$ (at 6 months), causing some infants got more nonmilk oral intake. Based on the deuterium oxide-tothe-mother technique, an infant is categorized as exclusively breastfed infant if the non-milk oral intake is $<25$ g. $\mathrm{d}^{-1}[3,10]$. The result of this study found that 11 infants $(36.7 \%)$ of 30 respondents at 3 months 1 infant $(3.3 \%)$ at 6 months who had the non-milk oral intake of $<25 \mathrm{~g}$. $\mathrm{d}^{-1}$. It meant, $36.7 \%$ was exclusively breastfed infants up to 3 months of age, then only 1 infant is an exclusively breastfed infant at 6 months of age. The milk intake of Indonesian infant EBF during the first 6 months of their life could be classified as sufficient $(76.7 \%)$. In the interview, $100 \%$ of mothers in this study assured that they exclusively breastfed their infants, but based on deuterium oxide-to-the-mother technique, it was found that $36.7 \%$ of their infants were fed non-milk intake of $25 \mathrm{~g} . \mathrm{d}^{-1}$. It clarified that the deuterium oxide techniques could prove accurately whether the mother exclusively breastfed her infants or not. In Indonesia, there is still a very strong influence from the parents / grandmother who advise the mother in order the infants since the age of 2 - 4 weeks after birth is introduced to foods such as honey, banana, "tajin" liquid (white liquid when cooking rice), especially if the baby is crying because of hunger due to mother's milk can not meet the needs of her baby. The reality in Indonesian society show that exclusive breastfeeding is not as easy as imagined. The belief in hereditary practices of giving a banana or other foods after a 2 monthold infant is a major obstacle in exclusive breastfeeding. In addition, health workers who help mothers during child birth often give formula milk and sugar water first to the infants when her mother is ready to breastfeed. According to N.H. Mabud et al. [22], only a few mothers give exclusive breastfeeding for 6 months, even the number of mothers who exclusively breastfed for less than one month the number is greater. There is no 
relationship between education level with duration of exclusive breastfeeding, as well as between knowledge of breast milk with the duration of exclusive breastfeeding. The percentage of fat mass (\% FM) of lactating mothers in Indonesia decreased from $18.4 \pm 8.1 \%$ to $15.5 \pm 11.2 \%$ at 6 months. This figure is lower than the \% FM of lactating mothers in several countries, for example in Sri Lanka is $24.8 \pm 6.1 \%$ [11] and in Brazil is $24.7 \pm 3.9 \%$ at 4 months [8]. This probably due to the nutrition intake of maternal were still not enough, so that this affected the lack of nutrients content in breast milk received by infants, whereas the infants need more nutrients from breast milk for infant growth. The results of this study are expected to reflect the condition of breastfeeding mothers to infants at study location, so that the lactating mothers pay more attention to their health and give good nutrition for their babies through exclusive breastfeeding program.

Total body weight (TBW) of Indonesian lactating mothers in the present study were $34.6 \pm$ $5.0 \mathrm{~kg}$ at 3 months and $35.9 \pm 4.8 \mathrm{~kg}$ at 6 months, they were higher than TBW of the lactating mothers at Srilangka, America, and Mexico. Bandara et al. reported that Srilangka lactating mother had TBW of $28.2 \pm 4.1 \mathrm{~kg}$, menwhile Butte et al. who cited by Bandara reported that American mothers has TBW of $31.2 \pm 3.3 \mathrm{~kg}$ and the Mexican mothers was between $27.2 \pm 2.9 \mathrm{~kg}$ and $28.5 \pm 1.9 \mathrm{~kg}$ at 4 - 6 months [11].

This study shows that there is no correlation between breast milk intake with maternal education. This fact is in accordance with the results reported by N.H. Mabud et al. [22]. The external influences more cause mothers lack the time to provide exclusive breast feeding. Eventhough mothers with higher education make them be more aware toward the health benefits concerning breastfeeding, they feed their babies for as long as possible. According to the "Victorian Brestfeeding Guidelines", an effective positioning and attachment of an infant for breastfeeding is essential for establishing and maintaining breastfeeding. Some babies will move positions or be assisted by the mother to achieve a breastfeeding position that will be comfortable for both mother and infant [23]. Breastfed babies cause more weight gain, there is a positive correlation of milk intake with body weight for age and weightfor-height, especially in boys. In this study, the increasing age of infants generally only slightly gaining weight, both in boys and girls.

Based on the results of researches in several countries, the volume of breast milk intakes by Indonesia infants aged up to 6 months were around 700 - 1105 g. $\mathrm{d}^{-1}$, this means that Indonesian babies got enough breast milk as does babies in other countries $\left(640-820\right.$ g.d $\left.{ }^{-1}\right)$. However, there were differences in weight gain of the Indonesian breastfed girls 3 months was smaller compared to EBF girls infants from Sri Lanka, as well as the boys and girls of 6 months age. The results of the validation of interviews with mothers showed that many mothers claimed that their babies received exclusive breastfeeding, but this $\mathrm{D}_{2} \mathrm{O}$ dilution method proved that these infants included nonexclusive categories.

\section{CONCLUSION}

In conclusion, the milk intake of Indonesian infant EBF during the first 6 months of their life could be classified as sufficient (76.7 \%), using deuterium oxide-to-the-mother technique, it was found that $36.7 \%$ of their infants were categorized as exclusively breastfed infant. The percentage of fat mass of Indonesian lactating mothers were lower than that reported in Sri Lanka and Brazil using the same methodology.

In the current study, exclusive breastfeeding practices with 30 pairs of mother-infant still shows that the conditions of exclusive breastfeeding practices have not been properly adhered to by mothers who deliver babies. It is recommended that "mother and baby health officer" in Indonesia are increasingly promoting in order mothers in urban and rural areas to breastfeed exclusively for up to 6 months.

\section{ACKNOWLEDGMENT}

This research was funded by BATAN, IAEA through IAEA-RAS 6073, and National Institute of Health Research and Development - The Ministy of Health. The authors would like to thanks Christine Slater Ph.D of International Atomic Energy Agency, Vienna, Austria for giving a valuable advice and support. The high appreciation also addressed to Dr. Anura V. Kurvad of St. Johns Research Institute - India for providing the facility of IR-MS instrument and the assistance, and to Dr. Sarita Devi and her colleagues for isotopes analysis. Special thanks also addressed to the researchers from National Institute of Health Research and Development - The Ministy of Health for contributing the respondents recruitment, and data \& samples collections, and to Head and member of "Tumbuh Kembang Anak" Cohort, Bogor City.

\section{REFERENCES}

1. R.E. Black, C.G. Victora, S.P. Walker et al., Lancet 382 (2013) 427. 
2. V.O. Owino, C. Slater and C.U. Loechl, Proc. Nutr. Soc. 43 (2017) 1.

3. G.N. Medoua, S.E.C. Nana, A.C.A. Ndzana et al., Matern. Child Nutr. 8 (2012) 330.

4. Anonymous, Indonesia Health Profile 2016, Ministry of Health Indonesia, Jakarta (2017) 138.

5. A. Halim, Z. Munasir and R. Rohsiswatmo, Sari Pediatr. 15 (2014) 345.

6. Devriany, Z. Wardani and Yuniar, Indonesia J. Public Health. 14 (2018) 44.

7. S.E. Moore, A.M. Prentice, W.A. Coward et al., J. Clin. Nutr. 85 (2007) 1075.

8. Anonymous, Stable Isotope Technique to Assess Intake of Human Milk in Breastfed Infants, IAEA Human Health Series No. 7, Vienna (2010).

9. T.M. Samuel, T. Thomas, S. Bhat and A. Kurvad, Eur. J. Clin. Nutr. 66 (2012) 1077.

10. V. Lopez-Teros, A.T. Limon-Miro, H. Astiazaran-Garcia et al., Nutrients 9 (2017) 1.

11. T. Bandara, M. Hettiarachchi, C. Liyanage et al., J. Nutr. (2015) 1325.

12. W.W. Wong and L.L. Clarke, J. Nutr. 142 (2012) 2057.

13. A. Norma, I. Machfoedz and O. Maharani, Journal Ners and Midwifery Indonesia $\mathbf{3}$ (2015) 91. (in Indonesian)
14. Anonymous, Analysis of Nutritional Problems and Achievement of Nutritional Improvement Program in the Location of Kuliah Kerja Profesi (KKP) of IPB's Students in Bogor Regency in 2014, Undergraduate Thesis, Bogor Agricultural Institute (2015).

15. T.N. Triatmaja, R. Damanik and I. Ekayanti, Indonesia J. Public Heal. 11 (2015) 92. (in Indonesian)

16. B. Kurniawan, Med. J. Brawijaya 27 (2013) 236. (in Indonesian)

17. D.A. Inayati, V. Scherbaum, R.C. Purwestri et al., Int. Breastfeed. J. 7 (2012) 1.

18. A. Ulfah, A.Z. Sahli and A. Nusadewiarti, Med. J. Lampung Univ. 3 (2014) 151. (in Indonesian)

19. N. Aziezah and M. Adriani, Media Nutr. Indonesia 9 (2013) 78.

20. M. Mazariegos, C. Slater and M. Ramirez-Zea, Food Nutr. Bull. 37 (2016) 494.

21. S.T.M. Andrade, D.A.L. Ciampo, I.R.L.D. Ciampo et al., Food Nutr. Sci. 5 (2014) 1196.

22. N.H. Mabud, J. Mandang and T. Mamuaya, J. Sci. Midwives 2 (2015) 51.

23. Suhartika and F. Djamilus, Midwife Journal 1 (2015) 41. (in Indonesian) 